\title{
Optimalisasi Aplikasi Macromedia Flash 8 Dalam Pembelajaran Kosakata Bahasa Arab
}

\author{
Muhammad Yusuf $^{(1)}$ \& Eka Dewi Rahmawati ${ }^{(2)}$ \\ elyusuf03@gmail.com,rahmania379@gmail.com
}

Universitas Islam Negeri Sunan Kalijaga, Yogyakarta, Indonesia

\begin{abstract}
ABSTRAK
Pembelajaran bahasa di era revolusi industri 4.0 juga mengalami dampak, misalnya pada penggunaan aplikasi dalam proses pembelajaran. Aplikasi tersebut biasanya digunakan sebagai media pembelajaran pada peningkatan keterampilan berbahasa atau komponen berbahasa, seperti kosa kata. Salah satu aplikasi yang bersifat mengefisienkan dan mengefektifkan pembelajaran bahasa Arab, khususnya pembelajaran kosa kata bahasa Arab adalah aplikasi macromedia flash 8. Aplikasi tersebut dapat digunakan untuk memecahkan kesulitan pembelajaran yang masih menjadi hambatan baik oleh pengajar dan pebelajar bahasa Arab di Indonesia. Tujuan dari tulisan ini adalah mengkaji aplikasi macromedia flash 8 dalam pembelajaran kosakata bahasa arab. Penelitian ini menggunaka metode rancang bangun berupa analisis kebutuhan, desain aplikasi, implementasi aplikasi, pengujian aplikasi, dan validasi aplikasi. Subjek penelitian adalah siswa MTS kelas IX. Hasil penelitian ini menunjukkan bahwa aplikasi macromedia flash 8 efektif meningkatkan kosa kata siswa khususnya yang berkaitan dengan materi puasa, idul adha, dan hobi yang disajikan dengan memanfaatkan teks, grafik, gambar, dan animasi.
\end{abstract}

Kata Kunci : Aplikasi; Macromedia Flash 8; Kosakata Bahasa Arab.

\begin{abstract}
Language learning in the era of industrial revolution 4.0 is also influenced by technology information development, for example, on using an application in the teaching and learning process. The application is usually using as a medium for improving language skills or language components, such as vocabulary. One application is efficient and effective in teaching the Arabic language, especially Arabic language vocabulary is a Macromedia flash 8 application. The application can be used to solve the problem which still constraint the Arabic teacher and also the students. This article aims to research the Macromedia flash 8 application in learning Arabic vocabularies. This research used a research design method with procedures, need analysis, application design, application implementation, application evaluation, and application validation. The subject of this research was Islamic junior student's grade IX. The result showed that Macromedia flash 8 application was effective in improving students' vocabulary, especially related to Islamic fasting, Ied Al-Adha, and hobby. They were presented using text, graphics, and animation.
\end{abstract}

Keywords: Application; Macromedia Flash 8; Arabic Language Vocabulary. 


\section{A. PENDAHULUAN}

Dinamisnya kehidupan menuntut segala aspek didalamnya untuk selalu ditinjau, tidak terkecuali ilmu kebahasaan.Di Indonesia kata bahasa yang melekat pada fakultas pendidikan bahasa diposisikan sebagai alat. Dengan kata lain, secara inhern pendidikan bahasa Arab bertujuan untuk mengarahkan siswa untuk mengoptimalkan alat tersebut sesuai dengan kepentingannya yang berkaitan dengan kapasitas dan kapabiltasnya dalam menjawab aneka problematika yang ada di masyarakat, baik berkaitan dengan realitas sosial, ekonomi, politik identitas, budaya, maupun agama (Mujib, 2010: 73). Dengan demikian, adagium yang menyatakan bahwa bahasa adalah alat membangun peradaban bangsa dapat terbukti kebenarannya.

Dalam konteks Nasional transfer pengetahuan bukan satu-satunya orientasi pembelajaran bahasa Arab. Ada beragam orientasi lain didalamnya, antara lain orientasi religius, akademis, profesionalisme atau praktis, dan orientasi ideologisekonomis (Nuha, 2012: 55; dan Maksudin, 2018: 193-194). Kendati demikian, prinsip instrumental pembelajaran bahasa Arab secara global hanya terdiri dari dua komponen. Pertama, maharah al-Lughowiyah. Kedua, anasir al-Lughoh (Asrori, 2013: 5). Bagaimanapun orientasinya, keterampilan dalam mengoperasionalkan bahasa Arab baik secara visual maupun verbal menjadi poin yang harus diberikan atensi.

Dalam diskursus keterampilan bahasa Arab, terdapat perbedaan perspektif dikalangan ahli mengenai faktor strategis yang mempengaruhi keterampilan berbahasa Arab siswa. Dalam perspektif Tarigan, penguasaan keterampilan berbahasa seseorang mempunyai interelasi dengan penguasaan mufradat yang dimilikinya. Probabilitas keterampilan berbahasa siswa berbanding lurus dengan penguasaan kosakatanya. Instrumen yang harus dijadikan pertimbangan dalam mengambil kebijakan mengenai gradasi siswa merupakan kualitas kemampuan berbahasa mereka. Sementara kualitas tersebut merupakan implikasi dari baiknya kompetensimufradatsiswa (Tarigan, 2015: 2). Sementara itu Muhammad Ismail Shiny (dalam Fatricia, 2018: 43) menyatakan bahwa mempelajari kosakata mempunyai posisi penting dalam pembelajaran bahasa Arab.Hal tersebut dikarenakan mufradat merupakan komponen asasi dalam sebuah bahasa. Narasi yang lain disampaikan oleh Ahmad Qomaruddin (2017: 21) yang menyatakan bahwa mempelajari kosakata mempunyai signifikansi yang tinggi terhadap keterampilan berbahasa siswa. Adapun dalam perspektif Syaiful Musthofa, sintaksis 
dan mufradat menjadi aspek penting dalam mempengaruhi penguasaan keterampilan berbahasa siswa (Mustofa, 2011: 4).Adapun artikulasi yang lebih komprehensif disampaikan oleh Permatasari dan Masri'ah (2019: 6) yang menyatakan bahwa selain sintaksis, morfologis, dan fonetik, kosakata merupakan salah satu komponen strategis dalam pembelajaran bahasa Arab.

Di Indonesia sudah sedari dulu pembelajaran bahasa Arab dilaksanakan, namun hasilnya sampai sejauh ini belum optimal. Ragam problem masih terus mewarnai, bahkan terkesan menghegemoni. Proses identifikasi problem tersebut dapat berangkat misalnya dari keunikan bahasa Arab sendiri yang berimplikasi pada sulitnya merumuskan metodologi. Sehingga disamping siswa memang kurang siap juga karena tidak mudahnya siswa dalam meresap pengetahuan di dalamnya. Selain itu juga disebabkan ragam karya mahasiswa bahasa Arab dirasa kurang kreatif dan inovatif. Karya ilmiah yang dibuat tidak menjawab tantangan keilmuan dan kelembagaan pendidikan bahasa Arab. Hal tersebut diperparah oleh kompetensi profesional, pedagogi, metodologi, pun kompetensi penelitian tenaga pendidik bahasa Arab yang cenderung kurang (Mujib, 2011: 6). Dalam narasi yang lain, Renti Yasmar (2017: 202) mengatakan bahwa salah satu faktor penghambat proses pembelajaran bahasa Arab berkaitan dengan operasionalisasi media pembelajaran. Sejauh ini optimalisasi media tradisional seperti buku pelajaran, papan tulis, dan spidol dirasa kurang kompatibel untuk menyajikan materi agar menarik. Oleh karenanya perlu inovasi baru berkaitan dengan media pembelajaran bahasa Arab sebagai bahasa asing yang dirasa adaptabel bagi siswa di Indonesia.Terlebih peran media konvensional dirasa tidak adaptable dalam proses pembelajaran bahasa pada konteks kekinian.

Dalam kaitan tersebut, perlu kiranya memadukan tekhnologi mutakhir dalam komputer untuk dijadikan media pembelajaran. Berdasarkan beberapa kajian yang telah dilakukan, penggunaan multimedia dapat mempermudah peran guru dalam metodologi pengajaran bahasa Arab(Yasmar, 2017: 202). Lebih lanjut Abdul Hamid (2008: 194196) berpendapat bahwa optimalisasi tekhnologi akan berimplikasi pada naiknya ketertarikan dan motivasi siswa dalam belajar bahasa Arab. Disamping itu lebih memberikan kesempatan siswa untuk independent dalam belajar, bahkan memberikan kesempatan kepada mereka untuk mengeksplorasi hal-hal yang baru. Adapun Salah satu formula yang ditawarkan berkaitan dengan pengembangan media berbasis pada 
tekhnologi adalah program macromedia flash. Macromedia flash merupakan akumulasi audio, gambar, animasi yang diproyeksikan menciptakan inovasi dalam pendidikan. Sehingga proses edukasi bersifat menarik, tidak stagnan, dan memudahkan proses presentasi materi di dalamnya. Selain itu dengan multimedia terciptalah independensi siswa dalam belajar materi bahasa Arab. Dapat dikatakan bahwasannya fitur multimedia mempunyai garansi lebih tinggi untuk membelajarkan secara efektif dan efesien daripada media tradisional (Yasmar, 2017: 203). Hal ini seperti hasil penelitian Rachman Azizi dkk, (dalma Sari, dkk, 2016: 27) yang menjelaskan bahwa penggunaan multimedia yang interaktif dapat menaikkan kualitas proses pun hasil belajar siswa. Dengan demikian terbukti bahwa multimedia interaktif memberikan pengaruh yang signifikan bagi tercapainya kompetensi dasar pun inti siswa dalam proses pembelajaran.

Bertitik dari narasi di atas, dalam penelitian ini penulis akan menawarkan multimedia pembelajaran kosakata bahasa Arab unutuk siswa MTs kelas IX semester ganjil. Adapun multimedia yang dikehendaki disini adalah multimedia interaktif atau macromedia flash 8. Multimedia tersebut disinyalir dapat membantu menyampaikan materi mufradat yang notabenenya merupakan aspek strategis dalam penguasaan keterampilan berbahasa Arab siswa secara efektif dan efesien.

\section{B. METODE PENELITIAN}

Dalam kajian ini, peneliti menggunakan metode rancang bangun. Dalam perspektif Pressman (dalam Buchori, dkk, 2015: 1), rancang bangun merupakan metode yang bermuara pada penciptaan atau perbaikan sesuatu yang sudah ada dengan cara mengidentifikasinya dan menerjemahkan hasilnya ke dalam bentuk perangkat lunak. Dalam penelitian ini peneliti berangkat dari analisis kebutuhan dalam pembelajaran mufradat yang dirasa perlu didialogkan dengan tekhnologi mutakhir, yaitu macromedia flash 8. Media ini berdasarkan kajian yang telah dilakukan oleh beberapa ahli dapat meningkatkan efektifitas dan efesiensi dalam proses pembelajaran kosakata, khususnya pada siswa MTs kelas IX. Adapun penelitian ini menggunakan model waterfall yang secara operasional terdiri dari: Pertama, analisa kebutuhan. Dalam hal ini peneliti menganalisa kebutuhan siswa dengan berdasar pada buku dan jurnal terkait yang menyatakan bahwa perlu memberikan tawaran baru dalam proses pembelajaran 
mufradat pada siswa kelas IX, tawaran tersebut penulis terjemahkan dengan mencoba menciptakan aplikasi macromedia flash 8. Selain itu, peneliti menganalisa materi pembelajaran mufradat pada siswa MTs kelas IX yang terdiridarimateriberkaitandenganpuasa, harirayaidul adha, dan hobi. Kedua, desain aplikasi yang terdiri dari representasi interface aplikasi. Dalam konteks ini, peneliti akan mendesain aplikasi dengan memasukkan unsur-unsur pembelajaran mufradat di dalamnya. Ketiga, implementasi aplikasi. Operasionalisasi langkah ketiga ini adalah dengan cara menginternalisasikan desain aplikasi yang telah didialogkan dengan unsur pembelajaran kosakata pada siswa MTs kelas IX kedalam perangkat lunak yang terdiri dari windows, dan macromedia flash8. Keempat, pengujian aplikasi. Dalam hal ini peneliti meminta kepada Mahasiswa Pascasarjana UIN Sunan Kalijaga program studi Pendidikan Bahasa Arab untuk menguji aplikasi yang telah peneliti tawarkan. Kelima, proses validasi. Adapun ahli yang menvalidasi aplikasi ini adalah dosen media pembelajaran pada program pascasarjana UIN Sunan Kalijaga Yogyakarta.

\section{HASIL DAN PEMBAHASAN}

Secara terminologi, terdapat sedikit distingsi antara media pembelajaran dan multimedia pembelajaran. Media pembelajaran adalah tekhnologi pembawa pesan yang dapat difungsikan dalam kelas-kelas pembelajaran misalnya dalam bentuk audio, video, film, buku, dan sebagainya (Asrori, 2015: 3). Sementara multimedia merupakan akumulasi dari beragamkomponen yang meliputi teks, grafik, audio, gambar, dan animasi dalam komputer atau lainnya yang dioptimalkan untuk menyampaikan materi dalam proses pembelajaran bahasa Arab (Mubarok, 2018: 70). Berdasarkan pengertian antara dua terma di atas, dapat diambil sintesis bahwa secara mendasar perbedaan antara keduanya berada pada struktur komponennya, dalam hal ini unsur multimedia lebih beraneka. Dengan kata lain, terma media lebih umum daripada multimedia. Adapun karakterisasi dalam pembuatan multimedia interaktif pembelajaran bahasa Arab adalah sebagai berikut:

1. Kejelasan urain materi

Dalam blue print pembelajaran, eksistensi materi harus diformulasikan berdasarkan komposisi yang sesuai dalam sebuah kemasan. Kejelasan dan mudah difahami adalah sesuatu yang harus dihadirkan dalam presentasi materi. Akumulasi dari beragam elemen 
yang meliputi fakta, prinsip, konsep, dan prosedur pembelajaran bahasa Arab membutuhkan kompetensi profesionalitas pengkonsep dalam menyajikan materi.

2. Daya tarik soft file multimedia interaktif

Perpaduan teks, huruf, warna, gambar, animasi, audio dan video berpotensi besar dapat mendorong siswa untuk tertarik terhadap proses pembelajaran dalam kelas.

3. Efesiensi pembelajaran

Multimedia interaktifsengaja didesain sedemikian rupa agar proses pembelajaran dapat berjalan efektif dan efesien. Dalam arti ia dibuat agar siswa dapat belajar secara mandiri kapan dan dimana saja. Dengan demikian pembelajaran akan lebih humanis dan demokratis.

4. Motivasi belajar bahasa Arab

Salah satu indikator multimedia yang baik mempunyai kekhasan yang tidak dimiliki multimedia yang lain, seperti menampilkan gambar dengan tema tertentu. Hal ini secara tidak langsung akan menyentuh sisi psikologis siswa untuk terus termotivasi dalam belajar dengan menggunakan multimedia ini.

5. Kemenarikan gambar/animasi

Indikator lain yang berkaitan dengan baiknya kualitas multimedia adalah kemenarikan gambar atau animasi di dalamnya. Gambar yang menarik misalnya dengan menyajikan tokoh kartun kegemaran siswa. Adapun animasi bisa dikatakan optimalisasi gambar dengan agar lebih menghidupkan daya imaginasi dalam durasi tertentu.

6. Warna

Secara fungsional, elemen visual berperan agar pembelajaran lebih menarik dan dapat memberikan stimulus terhadap imagi siswa. Warna berfungsi secara fisik bila visualisasinya mampu memperjelas indera penglihatan dalam menangkap objek yang dipresentasikan. Normalnya akan ada konstras antara objek dan backgroundnya. Sementara itu, fungsi psikologis warna akan eksis bila penampilannya berimplikasi pada munculnya emosi tertentu, misalnya sedih, gembira, tenang, sejuk, ceria, dan lain sebagainya. Oleh karenanya prinsip kreatifitas menjadi hal yang asasi dalam menyeleksi aneka warna yang sesuai dengan tema sekaligus tingkat perkembangan psikologi siswa sebagai subjek dari multimedia. Normalnya, anak remaja menyukai sesuatu yang terang dan cerah seperti biru laut, hijau daun, dan orange. 


\section{Motivasi mengerjakan latihan}

Adanya umpan balik berupa skor misalnya, dalam respon jawaban yang diberikan siswa akan menjadikannya termotivasi untuk mendapat jawaban yang benar(Ningsih, dkk, 2014: 68-70).

\section{Macromedia Flash 8}

Program Macromedia Flash 8 merupakan salah satu aplikasi yang berisi suatu program animasi yang telah banyak difungsikan designer untuk memproduksi dan mengkreasikan design yang profesional. Program ini bila dibandingkan dengan yang lain dirasa lebih fleksibel untuk mendesain animasi, sehingga tidak sedikit yang mengoptimalkan fungsi program tersebut. Pembuatan animasi interaktif atau noninteraktif bisa dengan menggunakan program macro media flash ini. Bagi seniman misalnya, program ini sangat membantu kinerja mereka sebab perannya sebagai tekhnologi yang bisa menghasilkan animasi visual yang bergerak (Andi, 2006: 1-2). Secara umum, macro media flash dioptimalkan untuk menghasilkan animasi web yang akan dipresentasikan dalam sebuah situs internet, dan pembuatan beragam animasi yang lain seperti animasi iklan dan film. Disamping itu, salah satu kelebihan dari program ini adalah bisa dikombinasikan dengan program lain seperti adobe photoshop, frontpage, macromedia dreamweaver, corel draw, dan lain sebagainya dalam rangka menghasilkan desain animasi yang menarik. Lebih lanjut Andi mengatakan bahwa keistimewaan program ini dibandingkan dengan program lain yang semisal di antaranya: 1) mampu membuat tombol-tombol interaktif dengan sebuah film ataupun objek yang lain, 2) mampu mentransformasikan transparansi warna dalam film, 3) mampu mentransformasikan suatu animasi kedalam bentuk yang lain, 4) mampu membuat gerakan animasi dengan berdasar pada pola yang telah ditetapkan, 5) mampu dikonversi dan dipublikasikan ke dalam beberapa format, misalnya: mov, swf, html, gif, jpg, pngg, exe, dan lain sebagainya(Andi, 2006: 1-2).

Flash dapat digunakan untuk membuat objek gambar menjadi animasi seolaholah gambar itu bergerak di sepanjang stage. Selain menggerakkannya sebagai animasi objek juga bisa diubah ukuran, warna, memutar, maupun mengubah opacity (kenampakan suatu objek dari jelas hingga lenyap). Animasi pada Flash dapat dilakukan dengan cara Frame by Frame dimana harus terlebih dahulu membuat gambar pada masing-masing frame, maupun dengan cara tweened Animation atau animasi berantara. 
Pada cara yang kedua ini hanya perlu membuat dua objek, yaitu objek awal dan objek akhir, sedang antara keduanya akan diselesaikan oleh Flash (Yudhiantoro, 2003: 8).

Adapun istilah-istilah umum dalam program Flash adalah sebagai berikut (Andi, 2006: 4).

Tabel 1. Istilah Umum Program Flash

\begin{tabular}{|c|c|}
\hline Istilah & Keterangan \\
\hline Properties & Bagian intruksi dari intruksi yang lain \\
\hline Animasi & Objek gerak yang didesain agar nampak lebih menarik \\
\hline Action & Intruksi pada suatu frame agar menjadi interaktif \\
\hline $\begin{array}{l}\text { Script } \\
\text { Movie Clip }\end{array}$ & Kombinasi animasi \\
\hline Frame & $\begin{array}{l}\text { Bagian layer yang berfungsi untuk mengatur desain } \\
\text { animasi }\end{array}$ \\
\hline Scene & $\begin{array}{l}\text { Layar yang berfungsi untuk menyusun beragam objem, } \\
\text { baik tulisan pun gambar. }\end{array}$ \\
\hline Time Line & Penampung layar \\
\hline Masking & $\begin{array}{l}\text { Suatu intruksi yang berfungsi menghilangkan sebuah } \\
\text { konten dari layer dimana isi layer tersebut akan tampak } \\
\text { saat movie dijalankan }\end{array}$ \\
\hline Layer & $\begin{array}{l}\text { Simbol tempat yang berfungsi menampung satu gerakan } \\
\text { objek sehingga bilahendak membuat gerakan lebih dari } \\
\text { satu objek sebaiknya diletakkan pada layer tersendiri }\end{array}$ \\
\hline Keyframe & Tanda yang berfungsi membatasigerakan animasi \\
\hline
\end{tabular}

Berikut ini adalah bagian-bagian dan fungsi dari elemen-elemen Macromedia Flash (Andi, 2006: 7).

Tabel 2. Bagian dan Fungsi Elemen Macromedia Flash

\begin{tabular}{ll}
\hline \multicolumn{1}{c}{ Nama Elemen } & \multicolumn{1}{c}{ Keterangan } \\
\hline ToolBox & $\begin{array}{l}\text { Bagian yang dapat difungsikan sebagai media } \\
\text { untuk mengambar dan memformat gambar }\end{array}$ \\
Panel/Jendela & $\begin{array}{l}\text { Bagian yang difungsikan sebagai instruktur } \\
\text { tambahan dari objek yang menjadi pilihan. } \\
\text { Properties } \\
\text { Tampilan Jendela Properties bersifat relatif }\end{array}$ \\
Timeline & $\begin{array}{l}\text { Bagian yang digunakan untuk mengatur susunan } \\
\text { layer }\end{array}$ \\
Layer & $\begin{array}{l}\text { Bagian yang difungsikan untuk mengatur susunan } \\
\text { dari objek yangtampak di stage }\end{array}$ \\
Panel/Jendela & Bagian aplikasi yang dapat difungsikan sebagai \\
Actions & instruktur Script pada objek yang menjadi pilihan. \\
\hline
\end{tabular}


Presentasi jendela actions bersifat relatif

Menu Beberapa intruksi yang difungsikan untuk mendesain atau membuat objek, animasi, layar, dan lain sebagainya.

Scane/Stage Layar yang dapat difungsikan untuk mengatur dan menyusun objek teks, gambar, animasi, ataupun movie

Frame

Bagian layer yang dapat difungsikan sebagai pengatur gerakan animasi

Panel/Jendela

Color Mixer

Bagian yang dapat difungsikan sebagai medium untuk mewarnai objek, baik solid pun gradasi.

Components

Tombol yang difungsikan sebagai daya tampung data

\section{Pembelajaran Kosakata Bahasa Arab Kelas IX}

Pembelajaran dalam perspektif Oemar Hamalik (1995: 37)merupakan transformasi tingkah laku individu sebab proses interaksi dengan lingkungannya. Sementara menurut Yatim Riyanto (2009: 5), pembelajaran merupakan akumulasidari proses mengamati, membaca, meniru, mengeksplorasi, mendengar, dan mengikutiarah tertentu. Dalamnarasi yang lain, Abdul Majid (2012: 109) berpendapat pembelajaran bermakna upaya untuk membelajarkan seorang atausekelompok orang melalui aneka usaha dengan menggunakan berbagai strategi, metode, dan pendekatan untuk mendapatkan tujuan yang telah direncanakan. Berdasarkan pengertian ahli di atas dapat diambil sintesis bahwa pembelajaran merupakan serangkaian aktivitas yang dilakukan siswa dengan berdasar pada instruksi guru yang telah memformulasikan tujuan, pendekatan, metode, dan strategi dalam kegiatan tersebut.

Adapun Kosakata atau dalam bahasa Arab disebut mufrodat, dalam bahasa Inggrisnya vocabulary adalah himpunan kata atau khazanah kata yang diketahui oleh seseorang atau entitas lain yang merupakan bagian dari suatu bahasa tertentu. kosakata ada yang mendefinisikan sebagai himpunan semua kata-kata yang dimiliki seorang individu yang berpotensi digunakan untuk menyusun kalimat baru. Khazanah kosakata dapat dijadikan indikator tingkat intelligensi seorang individu. Oleh karenanya, ia merupakan unsur asasi yang menentukan perkembangan kemampuan bahasa Arab siswa (Zaenudin, 2005: 89).

Dalam kontesk siswa MTs kelas IX, berikut materi pokok pembelajaran kosakata yang disusun oleh kementerian Agama Republik Indonesia: Idul Adha, Puasa Romadlon, Hijrah Nabi, Maulid Nabi, Hobi, Murid yang pandai, dan Hari libur 
(Hidayat, 2016). Namun dalam kajian ini, penulis hanya mengambil materi tentang Puasa Ramadhan, Idul Adha, dan hobi untuk dijadikan sampel dalam proses pembuatan multimedia interaktif.

\section{Perancangan}

Pembuatan multimedia ini diawali dengan membuat skema awal yang akan dijadikan dasar oleh penulis dalam menghasilkan multimedia interaktif dengan menggunakan macromedia flash 8 . Berikut visualisasi perancangangan multimedia dalam kajian ini: Gambar 1 Perancangan.
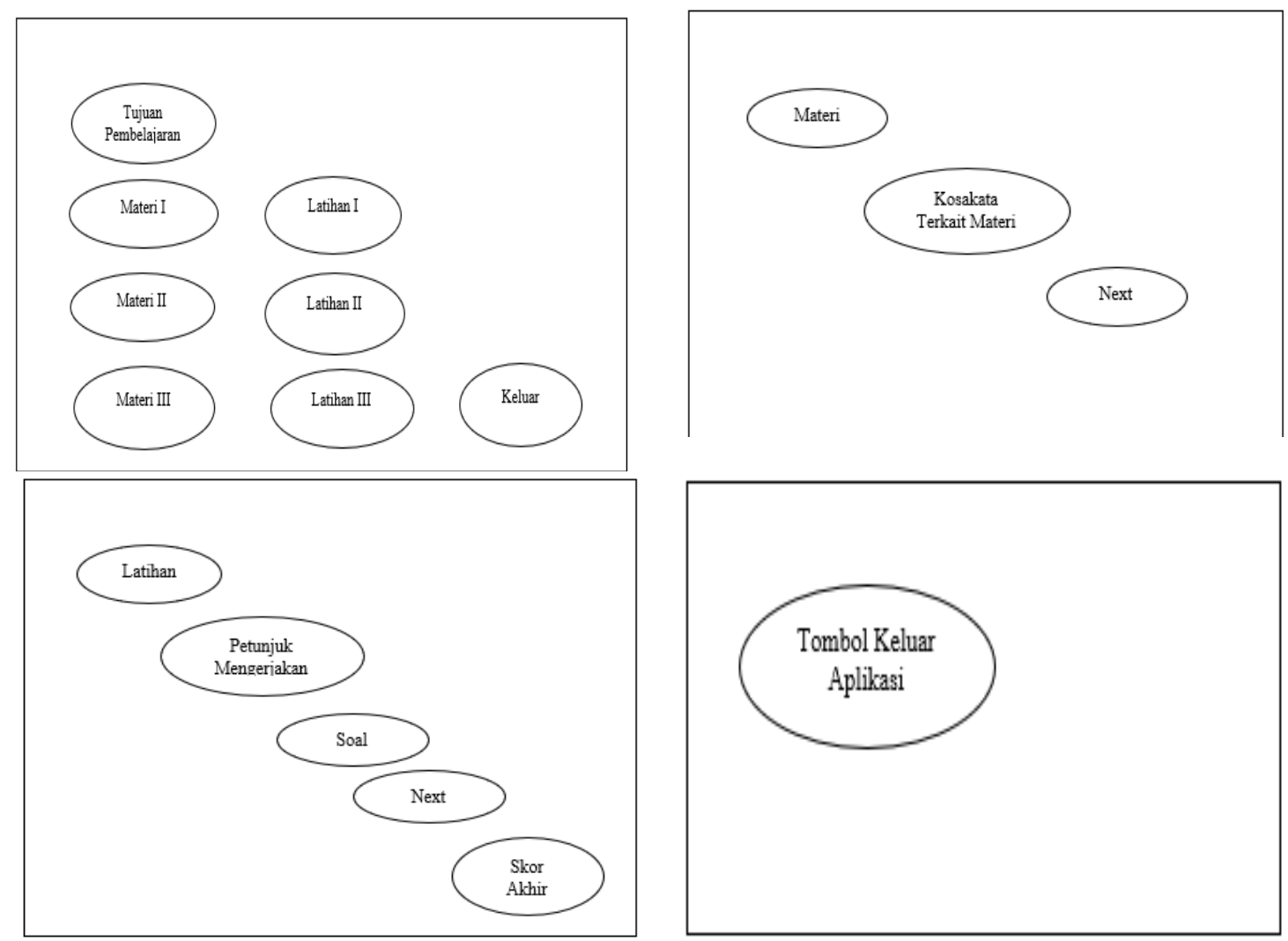

Gambar 1. Perancangan

Setelah perancangan dilakukan, maka tahap selanjutnya adalah membuat multimedia dengan menggunakan Adobe Flash.

\section{Menu Utama}

Tampilan pada menu utama terdapat dua scene, yaitu scene loading dan scene menu. Pada tampilan scene loading terdapat animasi Movie clip tanpa Action Script karena akan langsung berpindah ke scene menu dan memainkannya. 


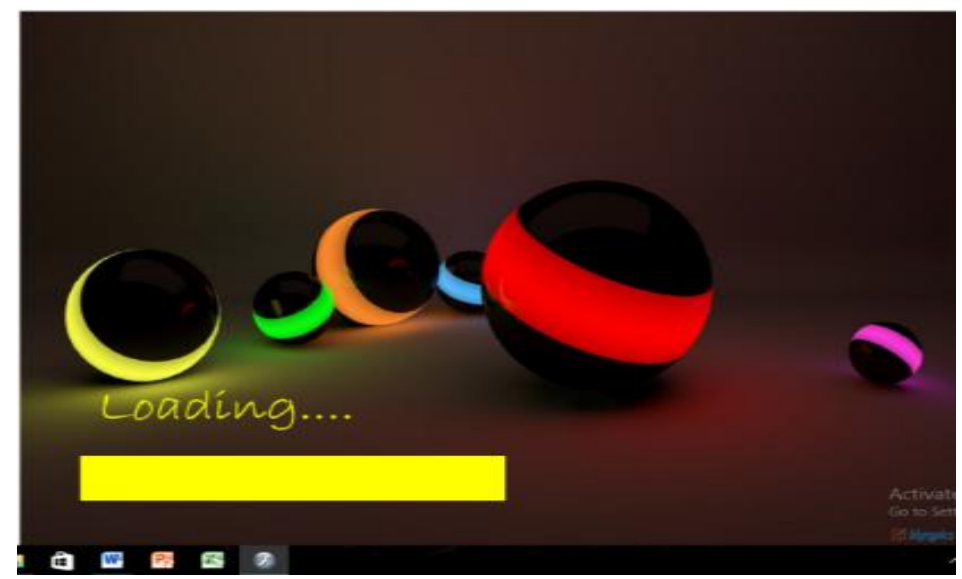

Gambar 2 Menu Utama

\section{Tujuan Pembelajaran}

Scene ini berisi tujuan pembelajaran, yaitu:

1. Siswa mengenal Mufradat baru yang berhubungan dengan materi-materi yang telah ditampilkan.

2. Siswa memahami arti dan maksud dari mufradat yang telah ditampilkan.

3. Siswa dapat mengerjakan latihan-latihan untuk mengetahui skor pemahaman siswa mengenai maufradat-mufradat yang telah ditampilkan.

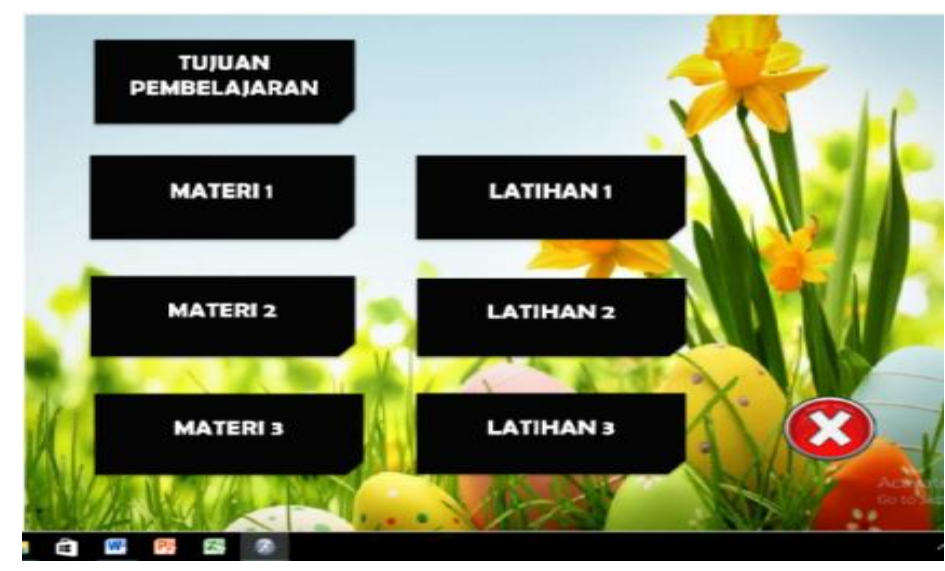

Gambar 3. Tujuan Pembelajaran

\section{Materi 1}

Pada menu 'Materi 1' ini terdapat beberapa frame, frame pertama berisi halaman judul 'Idul Adha'. Dan terdapat dua tombol yaitu tombol Home dan tombol Next. Adapun Actionscript pada tombol 'Home' adalah sebagaimana yang telah disebutkan, dan Actionsript pada tombol 'Next' adalah sebagai berikut. on (release) \{nextFrame() ; \}. Jika diklik maka akan masuk pada frame selanjutnya yang berisi tentang beragam kosakata yang berkaitan dengan topik materi I. 


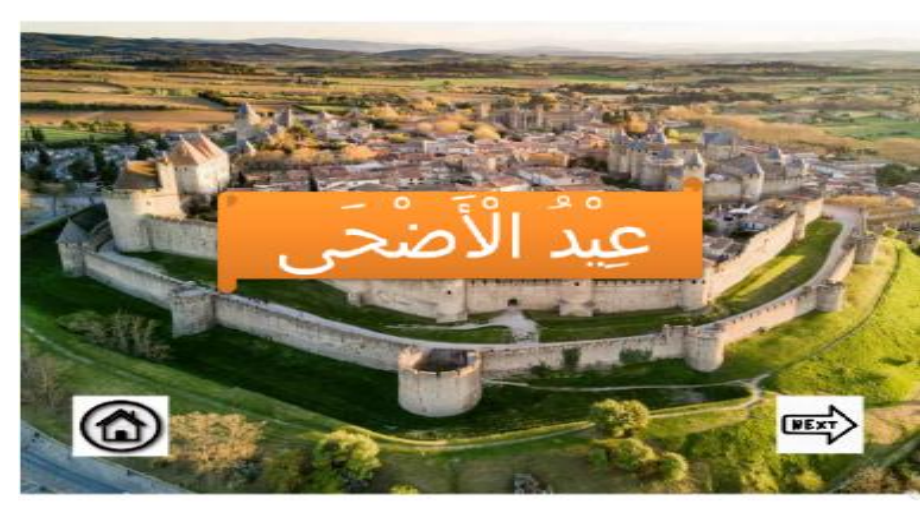

Gambar 4. Materi 1

\section{Materi 2}

Materi dua ini teridiri dari sepuluh frame yang berisi tentang materi kedua yakni 'Puasa Ramadhan'. Frame pertama merupakan halaman judul yang berisi dua tombol, yaitu tombol 'Home' yang jika diklik akan kembali pada menu utama dan tombol'Next' yang jika diklik akan menuju frame selanjutnya.

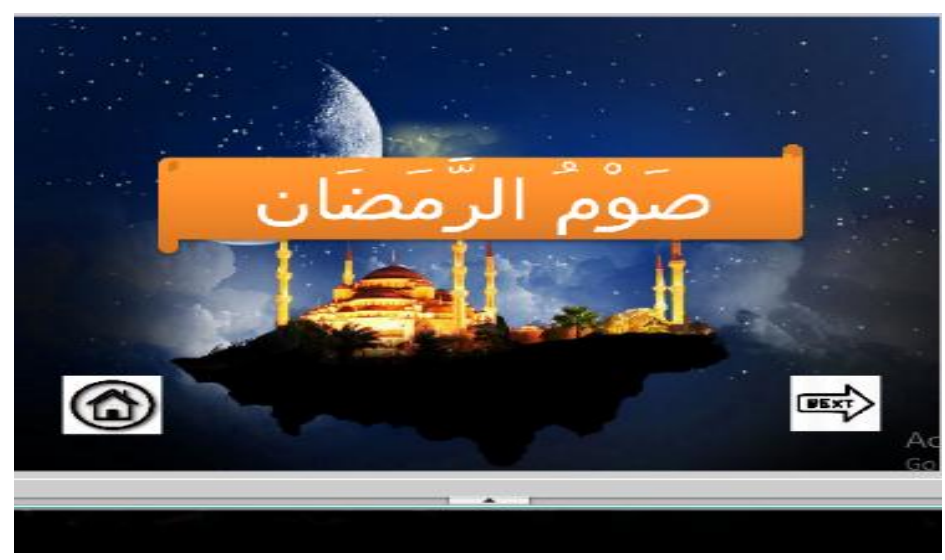

Gambar 5. Materi 2

\section{Materi 3}

Pada scene 'Materi 3' ini, terdapat sebelas Frame yang berisi judul dan materi mufradat untuk materi yang ketiga yaitu tentang Hobi-hobi. Pada frame pertama terdapat judul materi ketiga yaitu Hobi-hobi, dilengkapi dengan tombol 'Home' dan tombol 'Next' sebagaimana pada scene-scene sebelumnya. 


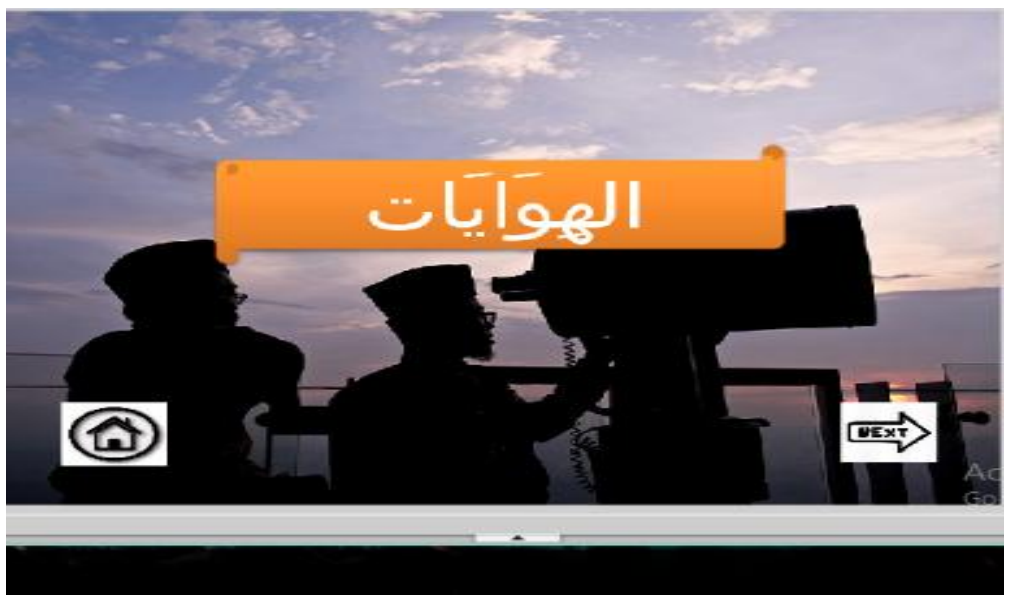

Gambar 6. Materi 3

\section{Latihan 1}

Latihan 1 ini berisi petunjuk mengerjakan soal dan soal-soal yang berkaitan dengan materi 1 tentang Idul Adha.

a. Frame pertama berisi petunjuk mengerjakan soal sebagai berikut:

b. Frame kedua berisi tombol 'Mulai' dengan action script:

on (release) \{nextFrame ();

c. Frame ketiga berisi soal pertama beserta lima tombol pilihan jawaban.

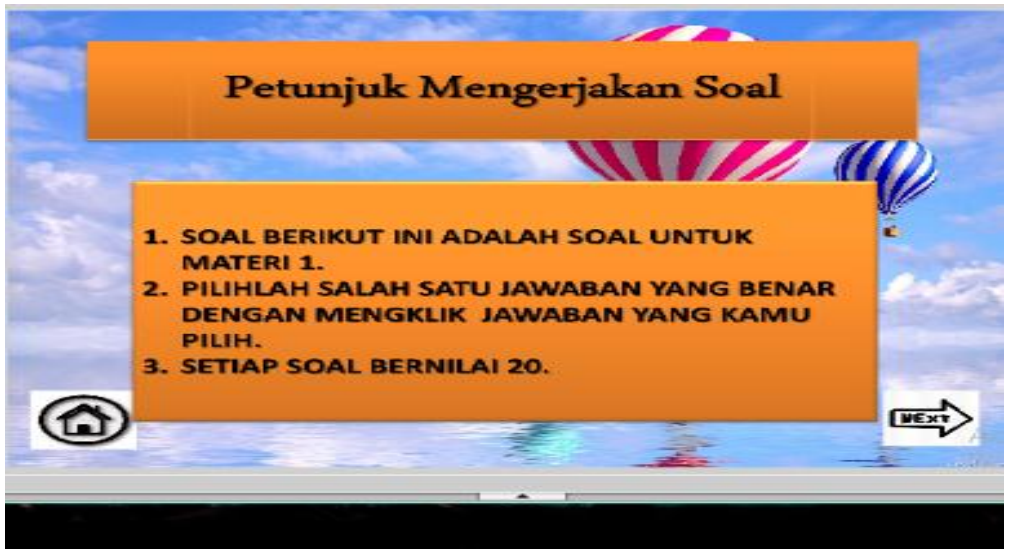

Gambar 6. Latihan 1

\section{Latihan 2}

Pada scene latihan 2 initerdapat sembilan frame, Latihan 2 ini berisi petunjuk mengerjakan soal dan soal-soal yang berkaitan dengan materi kedua yakni Puasa Ramadhan.

a. Frame pertamaberisipetunjukmengerjakansoalsebagaiberikut:

b. Frame keduaberisitombol 'Mulai' denganactionscript:

on (release) \{nextFrame (); 
c. Frame ketiga berisi soal pertama beserta lima tombol pilihan jawaban.

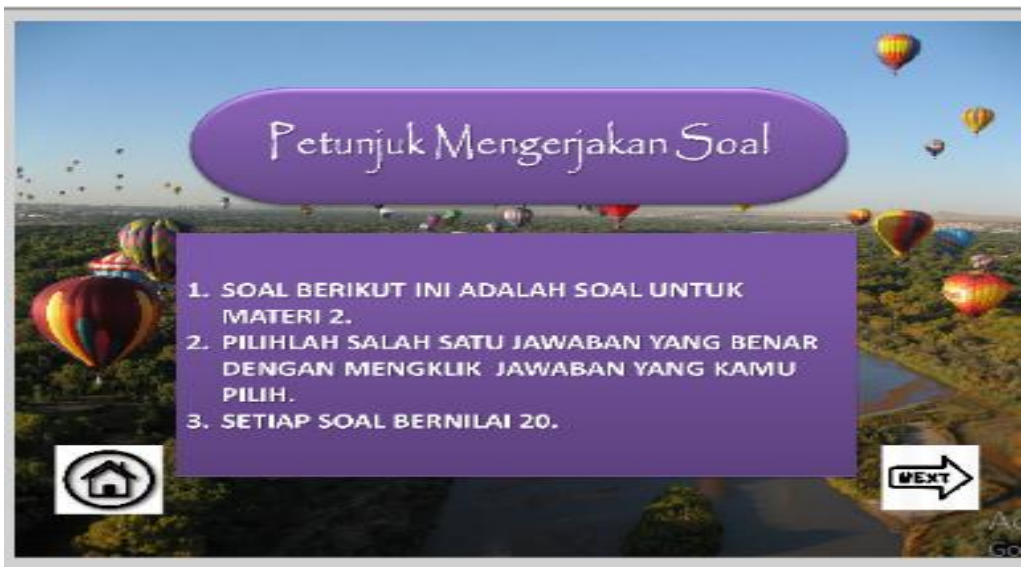

\section{Latihan 3}

Latihan 3 ini berisi petunjuk mengerjakan soal dan soal-soal yang berkaitan dengan materi ketiga tentang Hobbi.

a. Frame pertama berisi petunjuk mengerjakan soal sebagai berikut:

b. Frame kedua beri sitombol 'Mulai' dengan actions cript:

on (release) \{nextFrame ();

c. Frame ketiga berisi soal pertama beserta lima tombol pilihan jawaban.

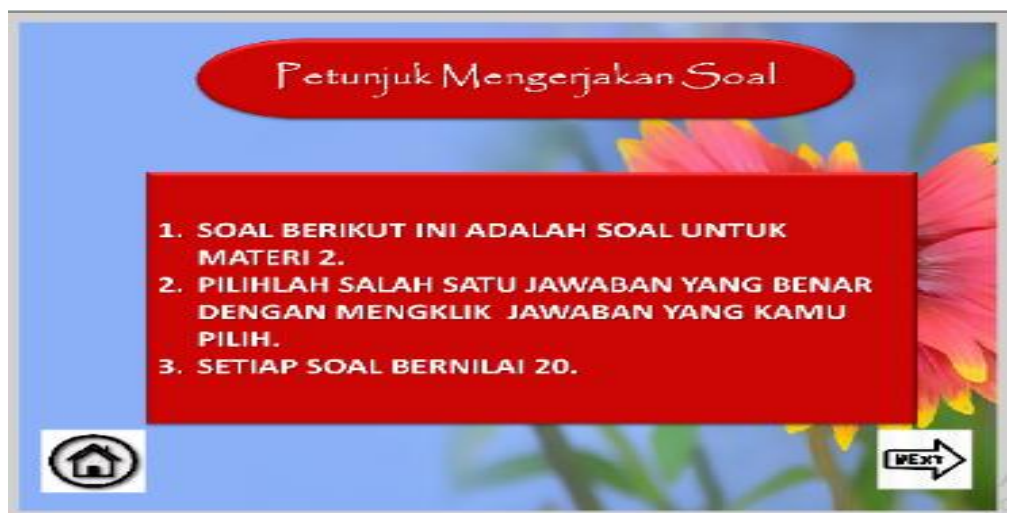

Gambar 8. Latihan 3

\section{Pilihan Keluar}

Ketika mengklik tombol keluar pada menu home, maka akan masuk terlebih dahulu pada halaman 'Keluar' yang berisi ucapan terimakasih sebagaimana berikut. Pada frame ini terdapat satu tombol yaitu tombol 'power' dengan action: on (release) ffscommand("quit", true). Apabila diklik tombol 'power', maka akan keluar dari multimedia interaktif yang sedang digunakan. 


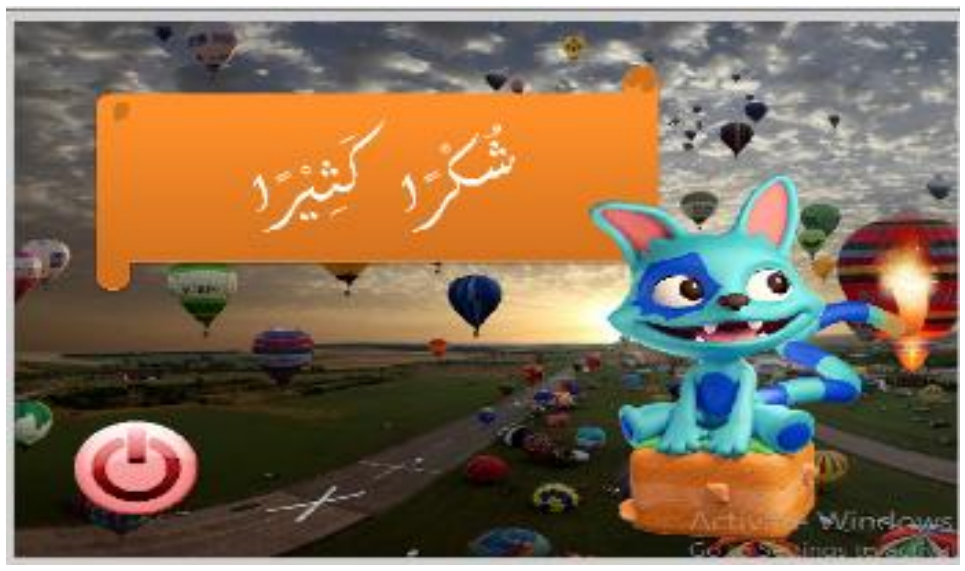

Gambar 9. Pilihan Keluar

\section{SIMPULAN}

Analisis kebutuhan, desain aplikasi, implementasi aplikasi, pengujian aplikasi, dan validasi aplikasi yang telah dilakukan menghasilakan kelayakan macromedia flash 8 ini untuk digunakan dalam proses pembelajaran kosakata bahasa Arab kelas IX MTs, khususnya yang berkaitan dengan materi puasa, idul adha, dan hobi yang disajikan dengan memanfaatkan teks, grafik, gambar, dan animasi yang terakumulasi dalam satua plikasi.

\section{DAFTAR PUSTAKA}

Andi dan Madcoms. 2006. Seri Aplikasi Macromedia Flash MX 2004 Membuat Animasi Movie Clip dengan Action Script. Yogyakarta: CV Andi Offset

Asrori, Mohammad. 2013. Pengembagan Kurikulum Bahasa Arab Di Pesantren. Malang: Uin Maliki Press.

Asrori, Imam dan Moh Ahsanudin. 2015. Media Pembelajaran Bahasa Arab. Malang: CV Bintang Sejahtera

Buchari, dkk. 2015. Rancang Bangun Video Animasi 3D Untuk Mekanisme Pengujian Kendaraan Bermotor di Dinas Perhubungan, Kebudayaan, Pariwisata. Jurnal: E-Journal Tekhnik Informatika, Vol. 6, No.1.

Darmawan, Deni. 2012. Inovasi Pendidikan "Pendekatan Praktik Tekhnologi Multimedia dan Pembelajaran Online”. Bandung: PT Remaja Rosdakarya. 
Fatricia, Iqfhayati dan Azizi Syafrudin Syafrawi. 2018. Perbandingan Efektivitas Penggunaan Media As-Shurah Al-Mufradah dan Media As-Shurah AlMurakhabah Serta Pengaruhnya Terhadap Peningkatan Penguasaan Kosakata. Jurnal: El-Ibtikar, Vol. 7, No. 2

Hamalik, Oemar. 1995. Kurikulum dan Pembelajaran. Jakarta : Bumi Aksara

Hamid, Abdul. Dkk. 2008. Pembelajaran Bahasa Arab "Pendekatan, Metode, Strategi, dan Media” Malang: UIN-Malang Press

Hermawan, Acep. 2011. Metodologi Pembelajaran Bahasa Arab. Bandung: PT Remaja Rosdakarya.

Hidayat, Ahmad. 2016. Bahasa Arab Kelas IX MTs Pendekatan Saintifik K13. Jakarta: Kementerian Agama Republik Indonesia.

Kurniawati, Inung Diah dan Sekreningsih Nita. 2018. Media Pembelajaran Berbasis Multimedia Interaktif Untuk Meningkatkan Pemahaman Konsep Mahasiswa. Jurnal: Journal Of Computer and Information Technology, Vol. 2, No. 1.

Majid, Abdul. 2012. Belajar dan Pembelajaran Pendidikan Agama Islam (Bandung: Remaja Rosdakarya.

Maksudin dan Qoim Nurani. 2018. Pengembangan Kurikulum Pembelajaran Bahasa Arab Yogyakarta: FITK-UIN Sunan Kalijaga.

Mubarok, Aziz dan Landung Sudarman. 2016. Aplikasi Multimedia Pembelajaran Bahasa Arab Untuk Madrasah Tsanawiyah Kelas VII. Jurnal: JUTIM, Vol. 2, No. 1.

Mujib, Fathul. 2010. Rekonstruksi Pendidikan Bahasa Arab 'Dari Pendekatan Konvensional Ke Integratif Humanis’. Yogyakarta: Bintang Pustaka Abadi

Mujib, Fathul dan Nailur Rahmawati. 2011. Metode Permainan-Permainan Edukatif dalam Belajar Bahasa Arab. Jogja: Diva Press

Mustofa, Syaiful. 2011. Strategi Pembelajaran Bahasa Arab Inovatif. Malang: UIN Maliki Press.

Ningsih, Nur Fitria, dkk. 2014. Pengembangan Multimedia Interaktif Pembelajaran Bahasa Arab Tingkat Madrasah Tsanawiyah. Jurnal; Pedagogi, Vol. 4, No. 2

Nuha, Ulin. 2012. Metodologi Super Efektif Pembelajaran Bahasa Arab. Yogyakarta: Diva Press. 
Permatasari, Nurul Hikmah dan Masri'ah. 2019. Pengaruh Permainan Kartu Huruf Terhadap Kemampuan Siswa Mengingat Kosakata Bahasa Arab di MTsN 11 Cirebon Jurnal: El-Ibtikar, Vol. 8, No. 1.

Qomaruddin, Ahmad. 2017. Implementasi Metode Bernyanyi Dalam Pembelajaran Mufradat. Jurnal: Kependidikan, Vol 1, No. 2

Riyanto, Yatim. 2009. Paradigma Baru Pembelajaran. Jakarta : Prenada Media Grup Sari, Noca Yolanda, dkk. 2016. Penggunaan Multimedia Pembelajaran Bahasa Arab Berbasis Aplikasi Macromedia Flash 8 Di TPA AL-Hidayah Sidoharjo Pringsewu. Jurnal: JPGMI, Vol. 2, No. 1.

Tarigan, Henry Guntur. 2015. Pengajaran Kosakata. Bandung: CV Angkasa.

Yasmar, Renti. 2017. Multimedia Interaktif Pembelajaran Bahasa Arab Siswa Madrasah Aliyah. Arabiyatuna: Jurnal Bahasa Arab, Vol. 1, No. 2

Yudhiantoro, Dhani. 2003. Panduan Lengkap Macromedia Flash MX. Yogyakarta: ANDI

Zaenudin, Radliyah. 2005. Metodologi dan Strategi Alternatif Pembelajan Bahasa Arab. Yogyakarta: Pustaka Rihlah Group 